\title{
Echocardiographic Evaluation of Biventricular Function in Patients with Euthyroid Hashimoto's Thyroiditis
}

\author{
Mehmet Bülent Vatan ${ }^{a} \quad$ Ceyhun Varım ${ }^{b} \quad$ Mustafa Tarık Ağaça Perihan Varım ${ }^{a}$ \\ Mehmet Akif Çakar ${ }^{a}$ Murat Aksoy ${ }^{a}$ Hakan Erkan ${ }^{c}$ \\ Sabiye Yılmaz ${ }^{a}$ Harun Kilic $^{a}$ Hüseyin Gündüz ${ }^{a}$ Ramazan Akdemir ${ }^{a}$ \\ Departments of a Cardiology and ${ }^{b}$ Internal Medicine, Sakarya University Training and Research Hospital, Sakarya, \\ and 'Department of Cardiology, Ahi Evren Cardiovascular Training and Research Hospital, Trabzon, Turkey
}

\section{Key Words}

Echocardiography · Euthyroid - Left ventricle .

Right ventricle $\cdot$ Thyroiditis

\begin{abstract}
Objective: The aim of this study was to evaluate the left (LV) and right (RV) ventricular function in euthyroid Hashimoto's thyroiditis (eHT) patients. Subjects and Methods: Forty-five patients diagnosed with eHT and 45 age- and gendermatched control subjects were enrolled in this study. Echocardiographic parameters reflecting RV and LV functions such as chamber dimensions, ejection fraction, fractional shortening, conventional and tissue Doppler-derived early and late filling velocities $\left(E, A, E^{\prime}, A^{\prime}\right)$, isovolumic relaxation (IVRT) and contraction (IVCT) times, ejection time (ET), deceleration time (DT), Tei index, pulmonary acceleration time (PACT) and tricuspid annular plane systolic excursion (TAPSE) of patients with eHT were compared to those of control subjects using the paired-samples $t$ test or Wilcoxon signedrank test. Results: Regarding the LV function, compared to the controls patients with eHT had a higher LV-Tei index (0.6 \pm 0.2 vs. $0.4 \pm 0.1, p<0.001)$, higher DT $(p<0.001)$ and IVRT
\end{abstract}

$(p<0.001)$ values, and higher $E / E^{\prime}$ ratios $(p=0.04)$. In contrast, the peak $E$ wave velocity $(p=0.02), E / A$ ratio $(p=0.01)$ and ET $(p=0.02)$ were significantly lower in the eHT group than amongst the controls. The RV, Tei index $(0.40 \pm 0.11 \mathrm{vs}$. $0.28 \pm 0.07, p<0.001)$, TAPSE $(2.0 \pm 0.3$ vs. $2.2 \pm 0.2 \mathrm{~mm}, \mathrm{p}<$ $0.001)$, PACT $(124.3 \pm 22.6$ vs. $149.4 \pm 18.3 \mathrm{~ms}, \mathrm{p}<0.001)$, $A^{\prime}(p=0.007)$ and IVCT $(p=0.001)$ were significantly higher in patients with eHT than the controls. However, the tricuspid E/A ratio $(p=0.01), E^{\prime}(p=0.03)$ and $E^{\prime} / A^{\prime}$ ratio $(p=0.001)$ were significantly lower in the eHT patients than the control group. Conclusions: This study demonstrated that both RV and LV functions were impaired in patients with eHT.

(c) 2015 S. Karger AG, Basel

\section{Introduction}

Hashimoto's thyroiditis (HT) is a common autoimmune disease characterized by the destruction of thyroid cells by a cellular and antibody-mediated autoimmune response [1]. In the cellular autoimmune process, excessively stimulated $\mathrm{T} \mathrm{CD} 4^{+}$cells, Th17 $\left(\mathrm{CD} 4^{+} \mathrm{IL}-17^{+}\right)$or T regulatory cells $\left(\mathrm{CD} 4^{+} \mathrm{CD} 25^{\text {hi }}{ }^{\text {FoxP }} 3^{+}\right)$are known to play

\begin{tabular}{ll}
\hline KARGER & $\begin{array}{l}\text { C) } 2015 \text { S. Karger AG, Basel } \\
1011-7571 / 15 / 0252-0143 \$ 39.50 / 0 \quad \text { Karger }\end{array}$ \\
$\begin{array}{l}\text { E-Mail karger@karger.com } \\
\text { www.karger.com/mpp }\end{array}$ & $\begin{array}{l}\text { This is an Open Access article licensed under the terms of the } \\
\text { Creative Commons Attribution-NonCommercial 3.0 Un- } \\
\text { ported license (CC BY-NC) (www.karger.com/OA-license), } \\
\text { applicable to the online version of the article only. Distribu- } \\
\text { tion permitted for non-commercial purposes only. }\end{array}$
\end{tabular}

Mehmet Bülent Vatan, MD

Department of Cardiology, Sakarya University Training and Research Hospital Adnan Menderes Street

TR-54000 Sakarya (Turkey)

E-Mail bulentvatan@ hotmail.com 
the most important role [2]. However, the development of self-antigens against thyroglobulin $(\mathrm{Tg})$ and thyroid peroxidase (TPO) has a minor role in the etiology of HT [2]. The disease is most common in middle-aged women, with a female:male ratio of approximately $3-4: 1$ [3]. The usual course of HT is a gradual loss of thyroid function [4]. The majority of patients with HT present with mild hypothyroidism [5]. Generally, thyroid function at presentation may significantly vary, ranging from euthyroidism to overt hypothyroidism. In the early course of disease, transient hyperthyroidism may occur owing to the thyroid follicular disruption and release of thyroid hormones [6].

Thyroid gland dysfunction affects the structure and function of the various organ systems [7]. It has been recognized that the most obvious clinical manifestations of thyroid disease are due to the direct effects of thyroid hormone on the heart and cardiovascular system [8]. Thyroid hormone promotes the expression of both structural and regulatory genes in the cardiac myocyte $[8,9]$. Thyroid hormone also has extranuclear genomic effects on the cardiac myocyte and on the systemic vasculature [10]. The genomic and nongenomic actions of thyroid hormone modulate cardiac function and cardiovascular hemodynamics. Both hypothyroidism and hyperthyroidism may result in changes in cardiac contractility, cardiac output, myocardial oxygen consumption, and systemic or pulmonary resistance [11]. These hemodynamic changes are associated with a remarkable impairment in both left ventricular (LV) and right ventricular (RV) function [12]. The impact of subclinical hypothyroidism on the cardiovascular system is similar, but less marked than those occurring in patients with overt hypothyroidism [13-17]. However, cardiovascular influence in patients with an euthyroid state is unclear. Recently, euthyroid HT (eHT) has been described in some patients with cardiovascular system disorders [18-21]. It has been suggested that cardiovascular influence in eHT may be related to the autoimmune disease as well as its endocrine consequences $[18,22]$. Hence, in this study we aimed to investigate the LV and RV performance of patients with eHT.

\section{Subjects and Methods}

\section{Subjects}

Forty-five patients diagnosed with eHT at the Endocrinology Clinic, Sakarya University Training and Research Hospital, Sakarya, Turkey, between February 2010 and June 2014, and 45 ageand gender-matched healthy subjects were enrolled in this study.
Healthy controls were selected from asymptomatic subjects admitted to the Preventive Medicine Clinic of the same hospital for screening purposes. The diagnosis of eHT was made based on the following laboratory criteria: thyroid-stimulating hormone (TSH), free tri-iodothyronine (fT3) and free thyroxine (fT4) levels within the normal range, anti-Tg antibody (Tg-Ab) and anti-TPO antibody (TPO-Ab) levels above cut-off values, and the ultrasonographic findings of hypoechoic thyroid structure and thyroid parenchymal heterogeneity. Exclusion criteria were subjects who had hypertension, coronary artery disease, valvular heart disease, atrial fibrillation, left bundle branch block or Wolf-Parkinson-White on their resting electrocardiogram, pulmonary, renal and liver disease. All subjects were evaluated through their history and a physical examination. Their weight and height were measured, BMI was calculated as weight in kilograms divided by meters squared $\left(\mathrm{kg} / \mathrm{m}^{2}\right)$, and blood pressure measurements were also recorded. Written informed consent was obtained from all participants. The Ethics Committee of Sakarya University School of Medicine approved this study.

\section{Biochemical Analysis}

Blood samples were drawn from the antecubital vein after $12 \mathrm{~h}$ of fasting into test tubes without anticoagulant and centrifuged for $10-15 \mathrm{~min}$ at 2,500-3,000 rpm, and serum was separated by decantation. Serum thyroid hormone levels (fT3, fT4, TSH), Tg-Ab and $\mathrm{TPO}-\mathrm{Ab}$ were measured by chemiluminescence immunoassay using Architect systems (Abbott, Wiesbaden, Germany), according to the manufacturer's instructions. The normal values in the laboratory were accepted as follows: fT3 $1.57-4.71 \mathrm{pg} / \mathrm{ml}$, fT4 8.1-19.1 $\mathrm{pg} / \mathrm{ml}$, TSH $0.35-4.94 \mu \mathrm{IU} / \mathrm{ml}, \mathrm{Tg}-\mathrm{Ab}<50 \mathrm{IU} / \mathrm{ml}$ and $\mathrm{TPO}-\mathrm{Ab}<10$ $\mathrm{IU} / \mathrm{ml}$.

\section{Thyroid Ultrasonography}

Ultrasound of the thyroid of all the patients was performed using the Toshiba Aplio 500 Ultrasound System (Toshiba Medical System Corporation, Tochigi, Japan) and the morphology was assessed by a specialized radiologist (C.V.). The assessment included basic morphometric, morphological grayscale imaging, as well as power Doppler evaluation of the thyroid gland. Grayscale morphological investigation of the thyroid included evaluation of echogenicity and nodularity. The vascularity of the thyroid gland was determined by power Doppler imaging.

\section{Echocardiographic Examination}

A single experienced operator (M.B.V.) using a Philips IE33 xMatrix Cardiac Ultrasound System with multifrequency transducers (Phillips, Andover, Mass., USA) performed standard echocardiographic examinations in all the patients. All measurements were recorded as the average of three cardiac cycles according to the standards of the American Society of Echocardiography [23]. Tissue Doppler studies were evaluated by pulsed-wave tissue Doppler (PW-TDI) echocardiography with a 2 - to $4-\mathrm{MHz}$ probe. On the apical 4 -chamber view, the PWTDI cursor was positioned parallel to the annular motion. The sample volume was placed $10 \mathrm{~mm}$ proximal to the annular level. Spectral pulsed-wave Doppler signal filters were adjusted to a Nyquist limit of $15-20 \mathrm{~cm} / \mathrm{s}$, using the minimal optimal gain to obtain the best signal-to-noise ratio. The monitor sweep speed was set at $50-100 \mathrm{~mm} / \mathrm{s}$ to optimize the spectral display of myocardial velocities. 
Table 1. Demographic, clinical and biochemical variables in the eHT and control groups

\begin{tabular}{lcccc}
\hline & $\begin{array}{l}\text { eHT group } \\
(\mathrm{n}=45)\end{array}$ & $\begin{array}{l}\text { Control group } \\
(\mathrm{n}=45)\end{array}$ & p value & $\begin{array}{c}\text { Reference } \\
\text { range }\end{array}$ \\
\hline Age, years & $29.8 \pm 9.0$ & $29.0 \pm 9.1$ & 0.15 & - \\
Female & $40(88.8)$ & $42(93.3)$ & 0.26 & - \\
BMI & $23.6 \pm 4.7$ & $23.6 \pm 3.9$ & 0.96 & - \\
Heart rate, beats/min & $74.9 \pm 15.9$ & $78.4 \pm 17.8$ & 0.11 & - \\
SBP, mm Hg & $105(100,120)$ & $105(100,110)$ & 0.43 & - \\
DBP, $\mathrm{mm} \mathrm{Hg}$ & $70(70,75)$ & $70(70,80)$ & 0.65 & - \\
fT3, pg/ml & $4.7 \pm 0.6$ & $4.6 \pm 0.6$ & 0.22 & $1.57-4.71$ \\
fT4, pg/ml & $14.7 \pm 2.0$ & $14.4 \pm 1.7$ & 0.50 & $8.1-19.1$ \\
TSH, mIU/l & $2.2 \pm 1.2$ & $2.2 \pm 1.3$ & 0.99 & $0.35-4.94$ \\
Tg-Ab, IU/ml & $24(11,158)$ & $4.5(2.4,7.6)$ & $<0.001$ & $<50$ \\
TPO-Ab, IU/ml & $135(32,297)$ & $3.1(2.3,4.5)$ & $<0.001$ & $<10$ \\
\hline
\end{tabular}

Values are presented as median \pm SD, $\mathrm{n}(\%)$ or median $(\mathrm{IQR}) . \mathrm{SBP}=$ Systolic blood pressure; $\mathrm{DBP}=$ diastolic blood pressure.

\section{Echocardiographic Evaluation}

LV ejection fraction (LVEF) was calculated by Simpson's method [23]. Left atrium size and LV end-diastolic and end-systolic dimensions were measured in the parasternal long-axis view. The left atrial phasic volume was measured by the modified biplane Simpson's method in 4 - and 2-chamber apical views. The maximum volume was measured at end-systole just before the opening of the mitral valve [23]. LV mass was assessed according to the Devereux method [24]. Using pulsed-Doppler velocity data of the LV inflow and outflow tract, peak early (E) and late (A) mitral inflow velocity, $\mathrm{E} / \mathrm{A}$ ratio, and deceleration time of E velocity (DT), isovolumic contraction time (IVCT), isovolumic relaxation time (IVRT) and ejection time (ET) were calculated. The myocardial performance index was calculated following analysis of Doppler time intervals as described by Tei et al. [25] (IVCT + IVRT/ET). Tissue Doppler echocardiography velocities of the LV were obtained at the lateral side of the mitral annulus in the pulsed-Doppler mode, and peak systolic (S'), early diastolic (E'), late diastolic (A') velocities and $E$ '/A' ratios were measured. E/E' ratios were also recorded thereafter, and taken as an index of raised LV filling pressures [26].

\section{$R V$ Echocardiographic Evaluation}

$\mathrm{RV}$ dimensions were determined in the 4-chamber view with the maximal and minimal medial-to-lateral dimension at the enddiastole. Right atrial dimensions were determined in the 4-chamber view at the end-systole. The two-dimensional RV ejection fraction was calculated using the modified Simpson's rule. The maximal right atrial volume was calculated using Simpson's method in the 4-chamber view at end-systole just before the opening of the tricuspid valve [23]. Tricuspid annular plane systolic excursion (TAPSE) was measured in the apical 4-chamber view using twodimensional maximal amplitude of the lateral tricuspid annular movement from the end-diastolic frame to the end-systolic frame. Pulsed-wave Doppler trans-tricuspid flow velocities (E and A tricuspid inflow velocity and E/A ratio) were recorded from the apical 4-chamber view. Pulmonary artery flow was measured by placing the pulsed wave Doppler sample volume at the annulus of the pulmonary valve, obtained from the short-axis view. From the pulse-wave Doppler profile, we measured the pulmonary acceleration time (PAcT) as the interval between the onset of ejection and the peak flow velocity. As PAcT has been shown to be heart rate dependent, corrected PAcT was calculated using the formula: PAcT/ $\sqrt{ }$ RR [27]. RV PW-TDI velocities were obtained at the tricuspid lateral annulus in the pulsed-Doppler mode, and S', E' and $A^{\prime}$ velocities and E'/A' ratios were measured. The isovolumic contraction time (IVCT), IVRT and ET were also derived from the PW-TDI recordings. On TDI, the time interval from the end to the onset of the tricuspid annular velocity pattern is equal to the sum of IVRT, IVCT and ET. ET was measured as the duration of the S' wave. The RV ventricle myocardial performance index (RV-Tei index) was calculated as IVCT + IVRT/ET [25].

\section{Statistical Analysis}

Statistical analysis was performed using SPSS for Windows version 20.0 (SPSS Inc., Chicago, Ill., USA). Analysis of the normality of the continuous variables was performed with the KolmogorovSmirnov test. Continuous variables are expressed as the mean \pm SD or median and interquartile ranges (IQR) according to whether they exhibited a Gaussian distribution. Categorical variables are expressed as proportions and/or percentages. Propensity score matching according to age and gender was done to find appropriate pairs for the eHT cases. The paired-sample t test, Wilcoxon signedrank test and $\chi^{2}$ test were performed when comparing the clinical and laboratory characteristics of the patients and control subjects. Spearman's correlation coefficients were used to determine the correlations between thyroid antibody levels and biventricular function. All $\mathrm{p}$ values were two sided with significance at $\mathrm{p}<0.05$.

\section{Results}

The demographic variables and thyroid hormone profiles of patients with eHT and the controls are summarized in table 1 . The baseline characteristics, such as age, 
Table 2. Two-dimensional/Doppler echocardiography and TDI LV analysis parameters

\begin{tabular}{|c|c|c|c|c|}
\hline & $\begin{array}{l}\text { eHT group } \\
(\mathrm{n}=45)\end{array}$ & $\begin{array}{l}\text { Control group } \\
(\mathrm{n}=45)\end{array}$ & $\mathrm{p}$ value & $\begin{array}{l}\text { Reference } \\
\text { range }\end{array}$ \\
\hline LVEF, \% & $65.7 \pm 2.9$ & $65.6 \pm 3.4$ & 0.78 & $55-75$ \\
\hline Fractional shortening, \% & $37.7 \pm 4.3$ & $37.1 \pm 3.6$ & 0.78 & $25-43$ \\
\hline LVEDD, cm & $43.7 \pm 4.2$ & $44.0 \pm 4.6$ & 0.70 & $37-56$ \\
\hline LVESD, cm & $27.9 \pm 3.2$ & $28.0 \pm 3.0$ & 0.82 & $22-38$ \\
\hline $\mathrm{E}, \mathrm{m} / \mathrm{s}$ & $0.9 \pm 0.2$ & $1.0 \pm 0.15$ & 0.02 & $0.6-1.2$ \\
\hline $\mathrm{A}, \mathrm{m} / \mathrm{s}$ & $0.7 \pm 0.2$ & $0.6 \pm 0.1$ & 0.18 & $0.4-0.8$ \\
\hline E/A ratio & $1.3 \pm 0.4$ & $1.5 \pm 0.3$ & 0.01 & $1-2$ \\
\hline $\mathrm{DT}, \mathrm{ms}$ & $228.9 \pm 29.1$ & $194.2 \pm 20.3$ & $<0.001$ & $150-200$ \\
\hline $\mathrm{ET}, \mathrm{ms}$ & $261.3 \pm 36.2$ & $280.0 \pm 32.6$ & 0.02 & - \\
\hline IVRT, ms & $95(87,103)$ & $77(70,86)$ & $<0.001$ & $60-100$ \\
\hline IVCT, ms & $47.3 \pm 17.4$ & $48.3 \pm 17.0$ & 0.77 & - \\
\hline LV myocardial performance (Tei) index & $0.6 \pm 0.2$ & $0.4 \pm 0.1$ & $<0.001$ & $0.30 \pm 0.08$ \\
\hline $\mathrm{E}^{\prime}, \mathrm{cm} / \mathrm{s}$ & $14.3 \pm 4,0$ & $13.6 \pm 2.8$ & 0.30 & $10.1-20.9$ \\
\hline $\mathrm{A}^{\prime}, \mathrm{cm} / \mathrm{s}$ & $7.9 \pm 2.9$ & $7.9 \pm 2.0$ & 0.89 & - \\
\hline E'/A' ratio & $2.0(1.3,2.5)$ & $1.7(1.3,1.9)$ & 0.10 & $1-2$ \\
\hline $\mathrm{E} / \mathrm{E}^{\prime}$ ratio & $7.5 \pm 1.9$ & $6.7 \pm 1.8$ & 0.04 & $<8$ \\
\hline Left atrial diameter, $\mathrm{mm}$ & $35.4 \pm 2.9$ & $35.1 \pm 3.0$ & 0.84 & $30-40$ \\
\hline Left atrial maximal volume, $\mathrm{ml} / \mathrm{m}^{2}$ & $37.6 \pm 13.4$ & $32.9 \pm 13.9$ & 0.86 & $18-58$ \\
\hline
\end{tabular}

Values are presented as median $\pm \mathrm{SD}$ or median $(\mathrm{IQR}) . \mathrm{LVEDD}=\mathrm{LV}$ end-diastolic diameter; $\mathrm{LVESD}=\mathrm{LV}$ end-systolic diameter.

sex, BMI, blood pressure, heart rate and thyroid hormone profiles (fT3, fT4 and TSH), were not different between the two groups.

\section{Function}

The eHT and control groups did not show any significant difference with respect to conventional two-dimensional echocardiographic parameters that included thicknesses of the interventricular septum and posterior wall, LV mass index, LV end-systolic and end-diastolic diameters and LVEF (table 2). Among the mitral inflow Doppler parameters, DT $(228.9 \pm 29.1$ vs. $194.2 \pm 20.3 \mathrm{~ms}, \mathrm{p}<0.001)$ and IVRT ( 95 vs. $77 \mathrm{~ms}, \mathrm{p}<0.001$ ) were significantly higher in the eHT group compared to controls. In contrast, the peak E wave velocity $(0.9 \pm 0.2$ vs. $1.0 \pm 0.15 \mathrm{~ms}, \mathrm{p}=0.02)$, E/A ratio $(1.3 \pm 0.4$ vs. $1.5 \pm 0.3, \mathrm{p}=0.01)$ and $\mathrm{ET}(261.3 \pm$ 36.2 vs. $280.0 \pm 32.6 \mathrm{~ms}, \mathrm{p}=0.02)$ were lower in the eHT group. The Tei index was markedly increased in the eHT group $(0.6 \pm 0.2$ vs. $0.4 \pm 0.1, \mathrm{p}<0.001)$. PW-TDI index analysis demonstrated that $E^{\prime}, A^{\prime}$ and the E'/A' ratio did not significantly differ between the two groups. Lateral annular E/E' was significantly increased in the eHT group in comparison with the controls $(7.5 \pm 1.9$ vs. $6.7 \pm 1.8, \mathrm{p}=0.04)$. In addition, the mean diameters and maximal volumes of the left atrium were similar between the groups.

\section{$R V$ Function}

The conventional and PW-TDI measurements obtained from the tricuspid valve and annulus are summarized in table 3. The RV diameter and RV ejection fraction did not differ between the eHT patients and the controls. Accordingly, with pulse wave Doppler echocardiography, the $\mathrm{E} / \mathrm{A}$ ratio (1.4 vs. $1.5, \mathrm{p}=0.01$ ) was significantly lower in the eHT group. When compared with the controls, the PW-TDI parameters, such as A' $(12.9 \pm 3.8$ vs. $11.1 \pm 3.3 \mathrm{~cm} / \mathrm{s}, \mathrm{p}=0.007)$, IVCT $(66.8 \pm 26.1$ vs. $44.7 \pm$ $21.5 \mathrm{~ms}, \mathrm{p}=0.001)$ and the RV-Tei index $(0.4 \pm 0.11$ vs. $0.28 \pm 0.07, \mathrm{p}<0.001)$, were significantly higher in patients with eHT. However, E' (15.5 \pm 3.9 vs. $17.2 \pm 4.2$ $\mathrm{cm} / \mathrm{s}, \mathrm{p}=0.03)$ and the E'/A' ratio ( $1.3 \pm 0.6$ vs. $1.6 \pm 0.5$, $\mathrm{p}=0.001)$ were significantly lower in the eHT group compared to the controls. TAPSE $(2.0 \pm 0.3$ vs. $2.2 \pm 0.2 \mathrm{~cm}$, $\mathrm{p}<0.001)$ and PAcT $(124.3 \pm 22.6$ vs. $149.4 \pm 18.3 \mathrm{~ms}$, $\mathrm{p}<0.001)$ were also significantly lower in patients with eHT. The mean diameters of the right atrium were similar between the groups. The maximal volumes of the right atrium were significantly higher in the eHT group as compared to the control group $(31.69 \pm 11.5$ vs. $23.7 \pm 5.4$ $\mathrm{ml} / \mathrm{m}^{2}, \mathrm{p}=0.002$ ). Spearman's correlation analysis revealed no correlation between thyroid autoantibody levels and RV and LV function. 
Table 3. Two-dimensional/Doppler echocardiography and TDI RV analysis parameters

\begin{tabular}{lcccc}
\hline & $\begin{array}{c}\text { eHT group } \\
(\mathrm{n}=45)\end{array}$ & $\begin{array}{l}\text { Control group } \\
(\mathrm{n}=45)\end{array}$ & p value & $\begin{array}{c}\text { Reference } \\
\text { range }\end{array}$ \\
\hline RVEF, \% & $68.8 \pm 5.9$ & $69.1 \pm 6.8$ & 0.42 & $43-65$ \\
Fractional shortening, \% & $37.4 \pm 4.7$ & $37.2 \pm 4.3$ & 0.82 & $32-60$ \\
RVEDD, mm & $26.0 \pm 3.4$ & $27.1 \pm 2.2$ & 0.08 & $2.7-3.3$ \\
RVESD, mm & $16.8 \pm 3.1$ & $17.6 \pm 2.4$ & 0.19 & - \\
E, m/s & $0.7(0.6,0.7)$ & $0.7(0.6,0.7)$ & 0.18 & $0.6-1.2$ \\
A, m/s & $0.5 \pm 0.1$ & $0.4 \pm 0.1$ & 0.03 & $0.4-0.8$ \\
E/A ratio & $1.4(1.2,1.5)$ & $1.5(1.3,1.7)$ & 0.01 & $1-2$ \\
TAPSE, cm & $2.0 \pm 0.3$ & $2.2 \pm 0.2$ & $<0.001$ & $1.5-2.0$ \\
PAcT, ms & $124.3 \pm 22.6$ & $149.4 \pm 18.3$ & $<0.001$ & $>130$ \\
ET, ms & $275.3 \pm 26.0$ & $284.8 \pm 36.0$ & 0.14 & - \\
IVRT, ms & $42.9 \pm 18.7$ & $36.2 \pm 18.4$ & 0.11 & $60-100$ \\
IVCT, ms & $66.8 \pm 26.1$ & $44.7 \pm 21.5$ & 0.001 & - \\
RV-Tei index & $0.40 \pm 0.11$ & $0.28 \pm 0.07$ & $<0.001$ & $0.26 \pm 0.08$ \\
E', cm/s & $15.5 \pm 3.9$ & $17.2 \pm 4.2$ & 0.03 & $10.1-20.9$ \\
A', cm/s & $12.9 \pm 3.8$ & $11.1 \pm 3.3$ & 0.007 & - \\
S', cm/s & $15.3 \pm 3.3$ & $15.9 \pm 2.7$ & 0.32 & $6.7-14.6$ \\
E'/A' ratio & $1.3 \pm 0.6$ & $1.6 \pm 0.5$ & 0.001 & $1-2$ \\
Right atrial dimension, mm & $30.1 \pm 9.2$ & $28.1 \pm 9.1$ & 0.79 & $28-46$ \\
Right atrial maximal volume, $\mathrm{ml} / \mathrm{m}^{2}$ & $31.69 \pm 11.5$ & $23.7 \pm 5.4$ & 0.002 & $12-35$ \\
\hline
\end{tabular}

Values are presented as median \pm SD or median (IQR). RVEF $=$ RV ejection fraction; RVEDD $=$ RV enddiastolic diameter; RVESD = RV end-systolic diameter.

\section{Discussion}

In the present study there were deleterious effects of eHT on RV systolic and diastolic functions. In addition, similar but less pronounced changes occurred in LV systolic and diastolic functions, thereby indicating that HT affected both RV and LV function regardless of normal thyroid levels.

Conventional methods indicating LV systolic function and TDI-derived diastolic parameters of LV were found to be normal in our study. However, the LV-Tei index was significantly elevated in the eHT group because of a prolongation of IVRT and ET shortening. Although the mean E/E' ratio in both the case and control groups was below the well-known threshold of 15 [26], it was still significantly higher in the eHT group compared to the controls, indicating a higher LV filling pressure in the eHT group. Previously, Akgul et al. [19] reported an impairment of global LV performance in patients with eHT. They showed an impaired Tei index and tissue Dopplerderived diastolic parameters despite normal findings by conventional echocardiography. In addition, they demonstrated that the $\mathrm{E} / \mathrm{E}$ ' ratio was found to be significantly increased in the eHT group than the controls. Our find- ings of LV dysfunction are comparable to the results published by Akgul et al. [19]. In contrast, we found that tissue Doppler-derived diastolic parameters of the LV were similar in eHT compared to our controls.

The impact of thyroid disorders on RV structure and function, especially in eHT patients, is still unknown. In this study, using TDI analysis of the tricuspid annulus, TAPSE, TDI-derived Tei index and the PAcT, as well as conventional two-dimensional/Doppler scan measurements, we showed that both systolic and diastolic indices of RV deteriorated in eHT. We found a longer IVCT, a higher RV-Tei index and A' value, and a lower TAPSE for our patients with eHT compared to the controls. In a study conducted by Arinc et al. [28] that included patients with diverse hormone statuses (overt hypothyroidism, subclinical hypothyroidism and hyperthyroidism), it was shown that tricuspid annular IVCT was increased in patients with overt and subclinical hypothyroidism. In contrast to our findings, they showed a significantly lower annular $A^{\prime}$ in patients with overt hypothyroidism. We thought that the differences between the two studies might be due to the different thyroid hormone statuses.

We also revealed that PAcT was significantly lower in eHT. The mean PAcT was $124 \mathrm{~ms}$ in the eHT group com- 
pared to $149 \mathrm{~ms}$ in the controls. It is known that PAcT provides an accurate estimate of the invasively measured systolic and mean pulmonary artery pressure, and a PAcT $<130 \mathrm{~ms}$ has been found to indicate elevated pulmonary artery pressure [27]. Previously, Sahin et al. [20] showed that pulmonary arterial pressure is higher in patients with eHT.

The underlying pathophysiologic mechanism leading to the cardiovascular effects of eHT have not yet been fully understood. Some possible mechanisms may explain the relationship between cardiac function and $\mathrm{eHT}$. First, autoimmunity associated with HT could be the culprit for cardiovascular influence, rather than the effects of the secreted hormones on the cardiovascular system. Autoimmunity-induced endothelial dysfunction and inflammation may have an important role in the pathogenesis of cardiovascular manifestations, such as hypertension, atherosclerosis and LV dysfunction [18, 21, 22, 29]. However, we did not find any correlation between thyroid antibody levels and biventricular functions in our study. Second, the majority of the cases of eHT are due to slow progressive thyroid failure, and it is widely acknowledged that patients with eHT will eventually progress to overt hypothyroidism [5]. Thus, occult and insidious progression to thyroid dysfunction in HT may be itself responsible for cardiovascular adverse effects even in subjects with normal fT3, fT4 and TSH levels. Third, the spectrum of clinical presentation may change during the natural course of the disease. Patients may have euthyroidism, hyperthyroidism or hypothyroidism, or may evolve from one condition to another over time [6]. Thus, the patients with eHT may be hypothyroid or hyperthyroid at baseline or at any time during the course of the disease. Therefore, LV and RV functional changes might be because of previous hypothyroidism or a hyperthyroid phase. Some limitations should be noted when interpreting our findings. The small sample size is the main limitation of the study. Secondly, although the patients were euthyroid at the time of echocardiographic examination, the changes observed might have resulted from previous hypothyroidism or hyperthyroid phases occurring outside a quiescent period.

\section{Conclusion}

In this study global RV and LV functions were impaired in patients with eHT. These changes were observed regardless of normal thyroid hormone levels.

\section{Disclosure Statement}

The authors have no conflicts of interest to declare.

\section{References}

1 Dayan CM, Daniels GH: Chronic autoimmune thyroiditis. N Eng J Med 1996;335:99107.

-2 Pyzik A, Grywalska E, Matyjaszek-Matuszek $\mathrm{B}$, et al: Immune disorders in Hashimoto's thyroiditis: what do we know so far? J Immunol Res 2015;2015:979167.

3 Weetman AP: The immunopathogenesis of chronic autoimmune thyroiditis one century after Hashimoto. Eur Thyroid J 2013;1:243250.

4 Huber G, Staub JJ, Meier C, et al: Prospective study of the spontaneous course of subclinical hypothyroidism: prognostic value of thyrotropin, thyroid reserve, and thyroid antibodies. J Clin Endocrinol Metab 2002;87:3221.

5 De Luca F, Santucci S, Corica D, et al: Hashimoto's thyroiditis in childhood: presentation modes and evolution over time. Ital J Pediatr 2013;39:8.

-6 Özen S, Berk Ö, Şimşek DG, et al: Clinical course of Hashimoto's thyroiditis and effects of levothyroxine therapy on the clinical course of the disease in children and adolescents. J Clin Res Pediatr Endocrinol 2011;3:192-197.

7 Iglesias P, Díez JJ: Thyroid dysfunction and kidney disease. Eur J Endocrinol 2009;160: 503-515.

8 Klein I, Danzi S: Thyroid disease and the heart. Circulation 2007;116:1725-1735.

9 Kiss E, Jakab G, Kranias EG, et al: Thyroid hormone-induced alterations in phospholamban protein expression: regulatory effects on sarcoplasmic reticulum $\mathrm{Ca}^{2+}$ transport and myocardial relaxation. Circ Res 1994;75:245251.

10 Davis PJ, Davis FB: Nongenomic actions of thyroid hormone on the heart. Thyroid 2002; 12:459-466.

11 Biondi B, Palmieri EA, Lombardi G, et al: Effects of thyroid hormone on cardiac function: the relative importance of heart rate, loading conditions, and myocardial contractility in the regulation of cardiac performance in human hyperthyroidism. J Clin Endocrinol Metab 2002;87:968-974.

12 Kosar F, Sahin I, Aksoy Y, et al: Usefulness of pulsed-wave tissue Doppler echocardiography for the assessment of the left and right ventricular function in patients with clinical hypothyroidism. Echocardiography 2006;23: 471-477.

13 Oner FA, Yurdakul S, Oner E, et al: Evaluation of ventricular functions using tissue Doppler echocardiography in patients with subclinical hypothyroidism. Turk Kardiyol Dern Ars 2011;3:129-136.

14 Biondi B, Klein I: Hypothyroidism as a risk factor for cardiovascular disease. Endocrine 2004;24:1-13.

15 Chen X, Zhang N, Cai Y, et al: Evaluation of left ventricular diastolic function using echocardiography and conventional Doppler echocardiography in patients with subclinical hypothyroidism aged $<60$ years: a meta-analysis. J Cardiol 2013;61:8-15. 
16 Korkmaz L, Sahin S, Akyuz AR, et al: Epicardial adipose tissue increased in patients with newly diagnosed subclinical hypothyroidism. Med Princ Pract 2013;22:42-46.

-17 Bakiner O, Ertorer ME, Haydardedeoglu FE, et al: Subclinical hypothyroidism is characterized by increased QT interval dispersion among women. Med Princ Pract 2008;17: 390-394.

18 McLeod DS: Autoimmune thyroid disease: a novel risk factor for atherosclerosis? Endocrine 2013;44:8-10.

19 Akgul E, Kutuk U, Ertek S, et al: Cardiac autonomic function and global left ventricular performance in autoimmune eauthyroid chronic thyroiditis: is treatment necessary at the euthyroid stage. Echocardiography 2011; 28:15-21.

20 Sahin M, Sade LE, Tutuncu NB, et al: Systolic pulmonary artery pressure and echocardiographic measurements in patients with euthyroid Hashimoto's thyroiditis. J Endocrinol Invest 2009;32:530-532.
21 Ciccone MM, De Pergola G, Porcelli MT, et al: Increased carotid IMT in overweight and obese women affected by Hashimoto's thyroiditis: an adiposity and autoimmune linkage? BMC Cardiovasc Disord 2010;10:10-22.

22 Jenkins RC, Weetman AP: Disease associations with autoimmune thyroid disease. Thyroid 2002;12:977-988.

23 Schiller NB, Shah PM, Crawford M, et al: Recommendations for quantification of the left ventricle by two-dimensional echocardiography. J Am Soc Echo 1989;2:358-367.

24 Devereux RB: Detection of left ventricular hypertrophy by M-mode echocardiography: anatomic validation, standardization, and comparison to other methods. Hypertension 1987;9:9-26.

25 Tei C, Dujardin KS, Hodge DO, et al: Doppler index combining systolic and diastolic myocardial performance: clinical value in cardiac amyloidosis. J Am Coll Cardiol 1996;28:658664 .
26 Nagueh SF, Middleton KJ, Kopelen HA, et al: Doppler tissue imaging: a non-invasive technique for evaluation of left ventricular relaxation and estimation of filling pressures. J Am Coll Cardiol 1997;30:1527-1533.

27 Rudski LG, Lai WW, Afilalo J, et al: Guidelines for the echocardiographic assessment of the right heart in adults: a report from the American Society of Echocardiography endorsed by the European Association of Echocardiography, a registered branch of the European Society of Cardiology, and the Canadian Society of Echocardiography. J Am Soc Echocardiogr 2010;23:685-713.

28 Arinc H, Gunduz H, Tamer A, et al: Evaluation of right ventricular function in patients with thyroid dysfunction. Cardiology 2006; 105:89-94.

29 Taddei S, Caraccio N, Virdis A, et al: Lowgrade systemic inflammation causes endothelial dysfunction in patients with Hashimoto's thyroiditis. J Clin Endocrinol Metab 2006;91: 5076-5082. 